\title{
Antifouling performance of mixed matrix PVDF membranes with mono-hydroxyl poly(dimethylsiloxane) (PDMS-OH) grafted silica nanoparticles ${ }^{\dagger}$
}

\begin{abstract}
Muayad Al-Shaeli, ${ }^{a}$ Stefan J. D. Smith, ${ }^{a, b}$, Shanxue Jiang, ${ }^{c, d}$ Huanting Wang, ${ }^{a}$ Kaisong Zhang $^{e}$ and Bradley P. Ladewig*f,g

In this study, surface-modified silica nanoparticles were used to improve the antifouling performance of PVDF ultrafiltration membranes. Fouling resistant nanoparticles were prepared by grafting monohydroxy-polydimethylsiloxane onto the surface of silica nanoparticles using Steglich esterification. The mixed matrix PVDF membranes were prepared with different nanoparticle concentrations to understand the effect of PDMS modified silica on membrane performance. The resulting hybrid membranes were characterised using a range of techniques including scanning electron microscopy (SEM), water contact angle (CA), porosity, and pore size measurements. Embedding silica nanoparticles resulted in a significant reduction in membrane fouling, including lower protein adsorption and a flux recovery ratio of $97 \%$. Although water flux was reduced by the addition of nanoparticles, the foulant rejection rate was increased significantly due to the changes in porosity and hydrophilicity of the membranes. Together, these results are of particular benefit to the ultrafiltration industry, where improved antifouling and flux recovery can help reduce operating and maintenance costs in these membrane processes.
\end{abstract}

\section{Introduction}

Membrane filtration is one of the most promising technologies for wastewater treatment.1.3 Among the various membrane filtration technologies, ultrafiltration (UF) membranes are widely used in wastewater treatment due to its high permeability, low operating and energy costs, and simple operation. 4.7 However, more widespread use of UF membranes is currently limited because of unacceptable levels of membrane fouling, which can rapidly reduce performance and increase maintenance costs. 8, [1] Primarily, UF membrane fouling is caused by the adsorption and deposition of proteins and biomacromolecules on the membrane surfaces and within its pores, which leads to drastic decline in water flux, shortened operating life and higher system costs. 12,15

Different types of polymers are used to prepare UF membranes, where polyvinylidene fluoride (PVDF) is a very common one due to its excellent chemical and thermal stability, high mechanical strength, and resistance against oxidation and corrosive me-

\footnotetext{
${ }^{a}$ Monash University, Department of Chemical Engineering, Clayton, VIC, 3800, Australia

${ }^{b}$ CSIRO, Manufacturing, Private Bag 33, Clayton South MDC, VIC 3169, Australia

${ }^{c}$ State Environmental Protection Key Laboratory of Food Chain Pollution Control, Beijing Technology and Business University, Beijing 100048, China

${ }^{d}$ Key Laboratory of Cleaner Production and Integrated Resource Utilization of China National Light Industry, Beijing Technology and Business University, Beijing 100048, China

${ }^{e}$ Institute of Urban Environment, Chinese Academy of Sciences, No. 1799, Jimei Road, Xiamen 361021, China

${ }^{f}$ Barrer Centre, Department of Chemical Engineering, Imperial College London, Exhibition Road, London SW7 2AZ, United Kingdom

${ }^{g}$ Institute for Micro Process Engineering (IMVT), Karlsruhe Institute of Technology, Hermann-von-Helmholtz-Platz 1, 76344 Eggenstein-Leopoldshafen, Germany

$\uparrow$ Electronic Supplementary Information (ESI) available: The original data for all figures, high resolution figures, and high-resolution SEM images, are available from https://doi.org/10.5281/zenodo.4882713

* Corresponding author: Dr. Bradley P. Ladewig, Email: bradley.ladewig@kit.edu
}

dia. 16.20 Unfortunately, PVDF is also particularly susceptible to organic fouling and biofouling due to the alternating $-\mathrm{CH}_{2}$ and $-\mathrm{CF}_{2}$ groups in the polymer which results in a relatively hydrophobic and low energy surface. When the membrane is in contact with water, foulants such as proteins, oils, and bacteria can easily attach to the membrane surface, causing a rapid degradation in water treatment performance. ${ }^{2122]}$ If the membrane surface can be modified to repel foulants and exhibit lower adhesion of biomolecules, the performance of PVDF-based UF membranes will be greatly improved. 21.23

The fouling resistance capability is based on the theory of interfacial surface free energy. There are various factors which can affect membrane antifouling performance. For example, the propensity to fouling can be decreased by increasing membrane hydrophilicity so water molecules are preferentially attracted to the surface. The water molecules which are strongly attached to the membrane surface can act as a barrier to foulants and prevent hydrophobic biomolecules from adhering to the membrane surface.1124 27 There are many agents which can improve membrane surface hydrophilicity, including but not limited to polyethylene glycol, 28 zwitterion-based materials, 29 and hydrophilic nanoparticles (e.g., $\mathrm{SiO}_{2}$ ) ${ }^{1530}$ In addition, the fouling properties are also influenced by the surface topology of membranes. Rough surfaces can disrupt the intermolecular forces which cause foulant adhesion. Rough surfaces also allow hydrodynamic forces, which are caused by the movement of water across membrane surface, to remove weakly bound foulant species, resulting in an intrinsically fouling resistant surface. 31 . 33

Polydimethylsiloxane (PDMS), a common type of polysiloxane, also shows antifouling properties, due to the rotational freedom of silicon-oxygen backbone within its structure. Also, PDMS has low surface energy and low small modulus of elasticity, which hinders foulant adsorption and reduces the difficulty of contami- 
nants removal during cleaning process. ${ }^{3435}$ A lot of studies used PDMS as an effective anti-fouling material. For example, Guo et al. ${ }^{36}$ developed a polyurethane based on PDMS, polytetrahydrofuran, and 7-amino-4-methylcoumarin, which demonstrated superior antifouling properties. Doan et al. $\frac{37}{}$ prepared a fibrous membrane using recycled polyethylene terephthalate, followed by surface coating of PDMS; the PDMS-modified membrane exhibited effective anti-fouling properties. However, it remains a challenge to simultaneously achieve antifouling performance and to prevent leaching and minimize pore blockage during membrane coating treatments. ${ }^{38}$ One solution to this issue is to incorporate PDMS-grafted inorganic nanoparticles into polymer membrane during solution casting, which can disperse the fouling resistant PDMS chains throughout the membrane instead of the exposed surface only. 4243

Static protein adsorption and flux recovery ratio are widely used to test the anti-fouling performance of the membranes. 44 For static protein adsorption test, bovine serum albumin is commonly used as the model foulant and the membrane is immersed into the BSA solution. ${ }^{45}$ Lower amount of BSA adsorption usually indicates better anti-fouling performance. For flux recovery test, faster and higher flux recovery usually indicates better antifouling properties. 46 A lot of studies have been carried out to study the anti-fouling performance of the prepared membranes using static protein adsorption and flux recovery tests. For example, Jiang et al. ${ }^{46}$ prepared polyamidoamine grafted polyacrylonitrile UF membrane which demonstrated excellent anti-fouling properties in terms of both a high flux recovery ratio and a good BSA rejection.

In this work, PDMS-grafted silica nanoparticles (PDMS-g-SiO 2 NPs) were prepared via Steglich esterification and then used to prepare asymmetric PVDF mixed matrix membranes. The antifouling performance, surface chemistry, and morphology of the resulting composite membranes were investigated. This paper aims to unite the antifouling properties of hydrophobic polymer (PDMS) and hydrophilic nanoparticles $\left(\mathrm{SiO}_{2}\right)$ to encourage surface segregation of desired moieties for mixed matrix PVDF membranes, which will be of particular benefit to the ultrafiltration industry.

\section{Results and discussion}

\section{Characterisation of PDMS-grafted silica nanoparticles}

According to the FTIR spectra in Figure 1 pristine and modified $\mathrm{SiO}_{2}$ showed two main absorption peaks at 1060 and $800 \mathrm{~cm}^{-1}$ which were ascribed to the stretching vibrations of $\mathrm{Si}-\mathrm{O}-\mathrm{Si}$ and Si-O, respectively. 47,50 The FTIR spectra results indicated that PDMS was grafted successfully onto the surface of $\mathrm{SiO}_{2}$ nanoparticles via the esterification reaction. 5051

The results of gravimetric analysis of pristine $\mathrm{SiO}_{2}$ and PDMSg- $\mathrm{SiO}_{2}$ nanoparticles is shown in Figure 2 The $\mathrm{SiO}_{2}$ sample exhibited two decomposition steps from $40-100^{\circ} \mathrm{C}$ and from above $350^{\circ} \mathrm{C}$, attributed to the elimination of physically adsorbed water and chemically bonded water (via hydrogen bonding). After grafting $\mathrm{SiO}_{2}$ with PDMS, the thermal decomposition of PDMS$\mathrm{g}-\mathrm{SiO}_{2}$ nanoparticless occurred between $300-700^{\circ} \mathrm{C}$ with the

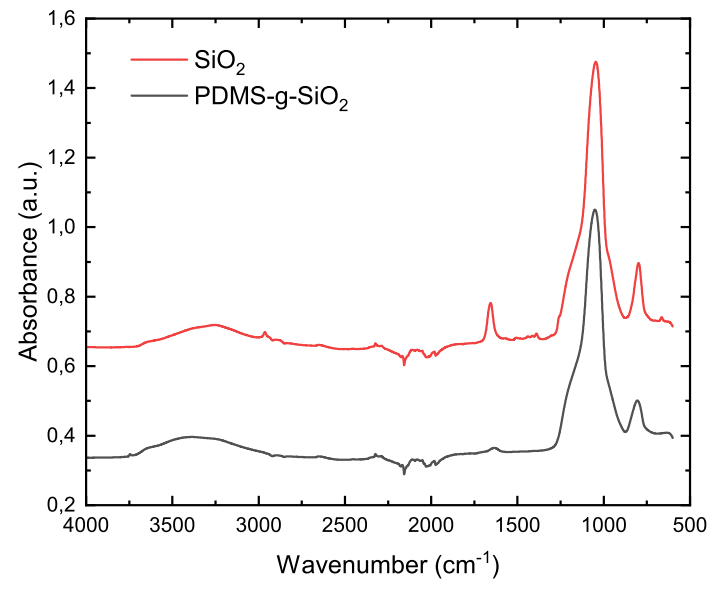

Fig. 1 FTIR-ATR spectra of $\mathrm{SiO}_{2}$ and PDMS-g-SiO 2 nanoparticles.

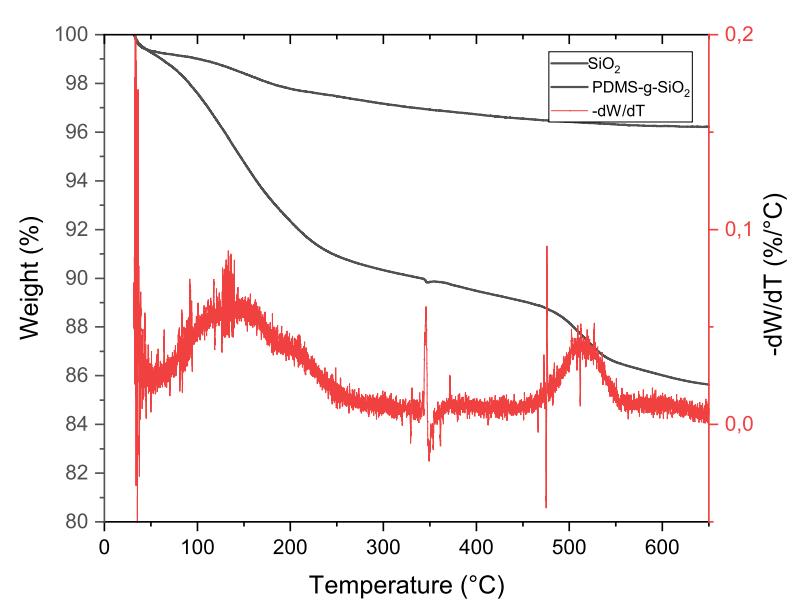

Fig. 2 Thermogravimetric analysis of $\mathrm{SiO}_{2}$ and PDMS-g-SiO 2 nanoparticles. The differential thermal weight loss $(-\mathrm{dW} / \mathrm{dT})$ is shown for PDMSg-SiO2 only.

weight loss of $10 \%$, which is due to the decomposition of grafted PDMS segments on the surface of $\mathrm{SiO}_{2}$ nanoparticles at $336^{\circ} \mathrm{C}$. Based on previous reports, the thermal degradation of PDMS polymer was around $336^{\circ} \mathrm{C} .{ }^{52}$ The TGA analysis result confirmed the successful grafting of PDMS on the surface of $\mathrm{SiO}_{2}$ nanoparticles.

\section{Characterisation of hybrid membranes}

As shown in Figure 3, all the PVDF mixed matrix membranes showed the characteristic absorption peaks at 1174, 1275 and $1405 \mathrm{~cm}^{-1}$ which corresponded to the symmetrical and asymmetrical stretching of $\mathrm{C}-\mathrm{F}$ and deformation vibration of $-\mathrm{CH}_{2}$ groups respectively. ${ }^{53}$ Interestingly, the characteristic adsorption peaks of silica were not revealed in Figure 3 , which could possibly be attributed to the uneven distribution of silica on the membrane surface and the relatively low amount of silica nanoparticles com- 


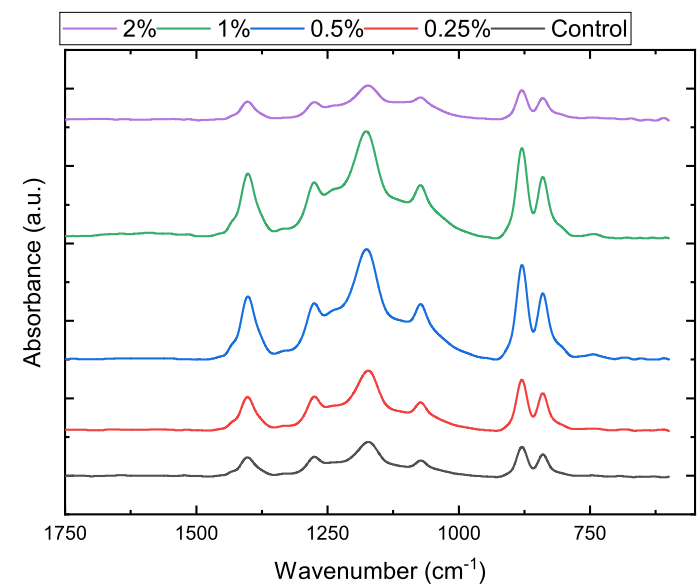

Fig. 3 FTIR-ATR spectra of pure PVDF (control) and mixed matrix PVDF membranes, where the percent loading indicates the quantity of PDMS-grafted $\mathrm{SiO}_{2}$ nanoparticles in the mixed matrix membranes.

pared to the PVDF membrane base.

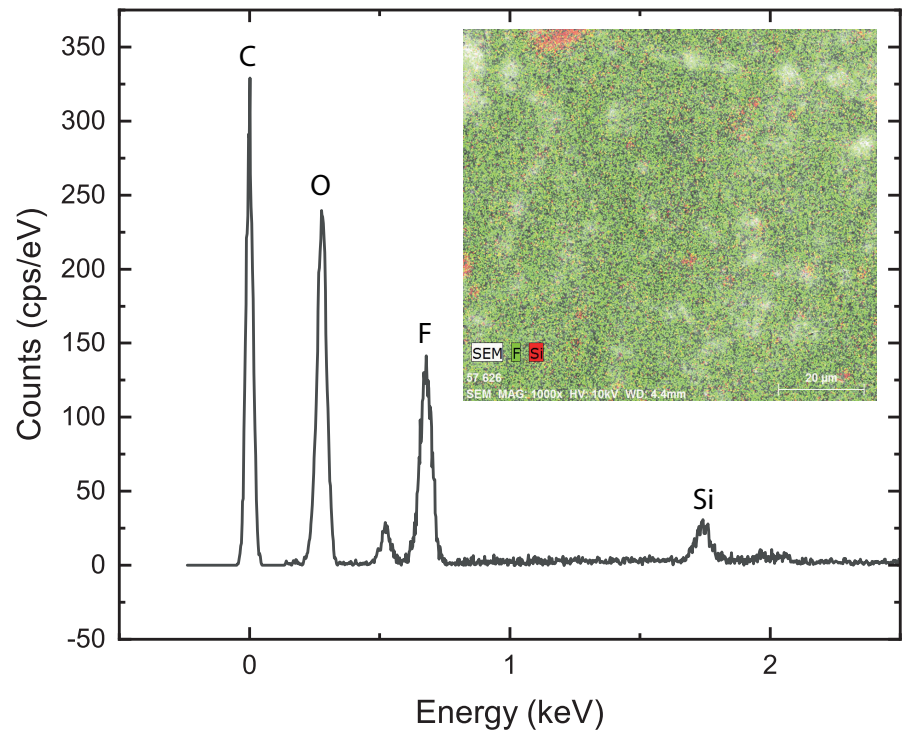

Fig. 4 EDX elemental analysis of the hybrid PVDF membrane $\mathrm{SiO}_{2}$ PDMS0.25\% PVDF. Inset: EDX elemental mapping, illustrating the good distribution of the nanoparticles through the mixed matrix membrane.

Figure 4 shows the EDX elemental analysis of a $\mathrm{SiO}_{2}$ PDMS0.25\% PVDF membrane. The $\mathrm{Si}$ element was observed at $1.75 \mathrm{KeV}$, which came from the inclusion of $\mathrm{SiO}_{2}$ in the membrane matrix. The Peaks at $0.3 \mathrm{keV}$ and $0.7 \mathrm{keV}$ arise from carbon (C) and fluorine (F) in the PVDF structure. As shown in the inset elemental map, $\mathrm{SiO}_{2}$ (red colour) was uniformly distributed on the membrane surface. This result confirmed the presence of well-distributed nanoparticles within the membrane matrix.

The cross-sectional morphology of the control and modified PVDF membranes is shown in Figure 5, A typical asymmetric structure was observed for all the PVDF membranes, including a thin skin layer on the top, followed by a larger finger-like struc- ture and a sponge-like structure at the bottom. It seems that a significant difference in finger-like structure was observed after incorporation of nanoparticles. However, this was not necessarily the case. It was possibly due to the uneven distribution of pore structures in the base PVDF membranes. In other words, the change in the depth of finger-like structure is intrinsic to the base membrane and is not caused by nanoparticle incorporation. The control PVDF showed no trace of silica NPs within the membrane matrix while mixed matrix PVDF membranes showed the presence of silica nanoparticles within the membrane matrix, especially for membranes with $1 \%$ and $2 \%$ loadings (See Figure S1). The difference in surface properties was possibly due to the addition of nanoparticles during membrane preparation which changed the interactions within the membrane.

The surface wettability is one of the most important aspects affecting the separation performance and antifouling property of ultrafiltration membranes. Generally, the hydrophilicity of PVDF membranes was evaluated by contact angle measurement and higher hydrophilicity results in a smaller water contact angle. Table 1 shows the results of contact angle, porosity and pore size of control and modified PVDF membranes. It can be seen that mixed matrix PVDF membranes showed a slight increase in contact angle (CA) in comparison with the control PVDF that showed $75.4^{\circ}$ due to non-polarity of the dimethylsiloxane groups. ${ }^{[54}$ The increase in CA value was possibly due to the difference in surface free interfacial energy between PVDF and PDMS. The mean surface pore size of membranes was reduced only slightly from 22.1 $\mathrm{nm}$ for control PVDF to $21.1 \mathrm{~nm}$ for $\mathrm{SiO}_{2} \mathrm{PDMS} 2 \% \mathrm{PVDF}$ membrane when the contents of PDMS-g-SiO ${ }_{2}$ increased. The porosity of membranes also decreased from about $85 \%$ for control PVDF to $78 \%$ for $\mathrm{SiO}_{2} \mathrm{PDMS} 2 \% \mathrm{PVDF}$, which could possibly cause the decrease in pure water flux.

Table 1 Porosity, contact angle, MWCO and pore size for all hybrid PVDF membranes, where the percent value indicates the loading of PDMS-g- $-\mathrm{SiO}_{2}$ in mixed matrix membranes

\begin{tabular}{lllll}
\hline Membrane & $\begin{array}{l}\text { Porosity } \\
(\%)\end{array}$ & $\begin{array}{l}\text { Contact angle } \\
\left({ }^{\circ}\right)\end{array}$ & $\begin{array}{l}\text { MWCO } \\
(\mathrm{kDa})\end{array}$ & $\begin{array}{l}\text { Pore size } \\
(\mathrm{nm})\end{array}$ \\
\hline PVDF +LiCl & 85.3 & $75.4 \pm 1.2$ & 188 & 22.1 \\
$0.25 \%$ & 83.8 & $77.7 \pm 0.3$ & 186 & 21.8 \\
$0.5 \%$ & 80.3 & $78.0 \pm 0.7$ & 182 & 21.7 \\
$1.0 \%$ & 79.9 & $80.5 \pm 0.8$ & 180 & 21.6 \\
$2.0 \%$ & 78.0 & $82.9 \pm 1.3$ & 178 & 21.1 \\
\hline
\end{tabular}

\section{Separation performance of hybrid membranes}

Separation performance of hybrid PVDF membranes was investigated and the results of pure water flux and BSA rejection for control and modified PVDF membranes are shown in the Figure6 The flux for control membrane is higher than the pristine PVDF membranes due to the use of $\mathrm{LiCl}$ as a hydrophilic modifier. After PDMS-g- $\mathrm{SiO}_{2}$ was added, the hybrid membranes showed a gradual reduction in water flux. This was possibly because that the viscosity of the casting solution increased as a result of increasing the content of PDMS-g-SiO 2 NPs, thereby delaying the phase separation process and resulting in a lower porosity as confirmed in Table 2. The alteration in surface morphology of membrane also 

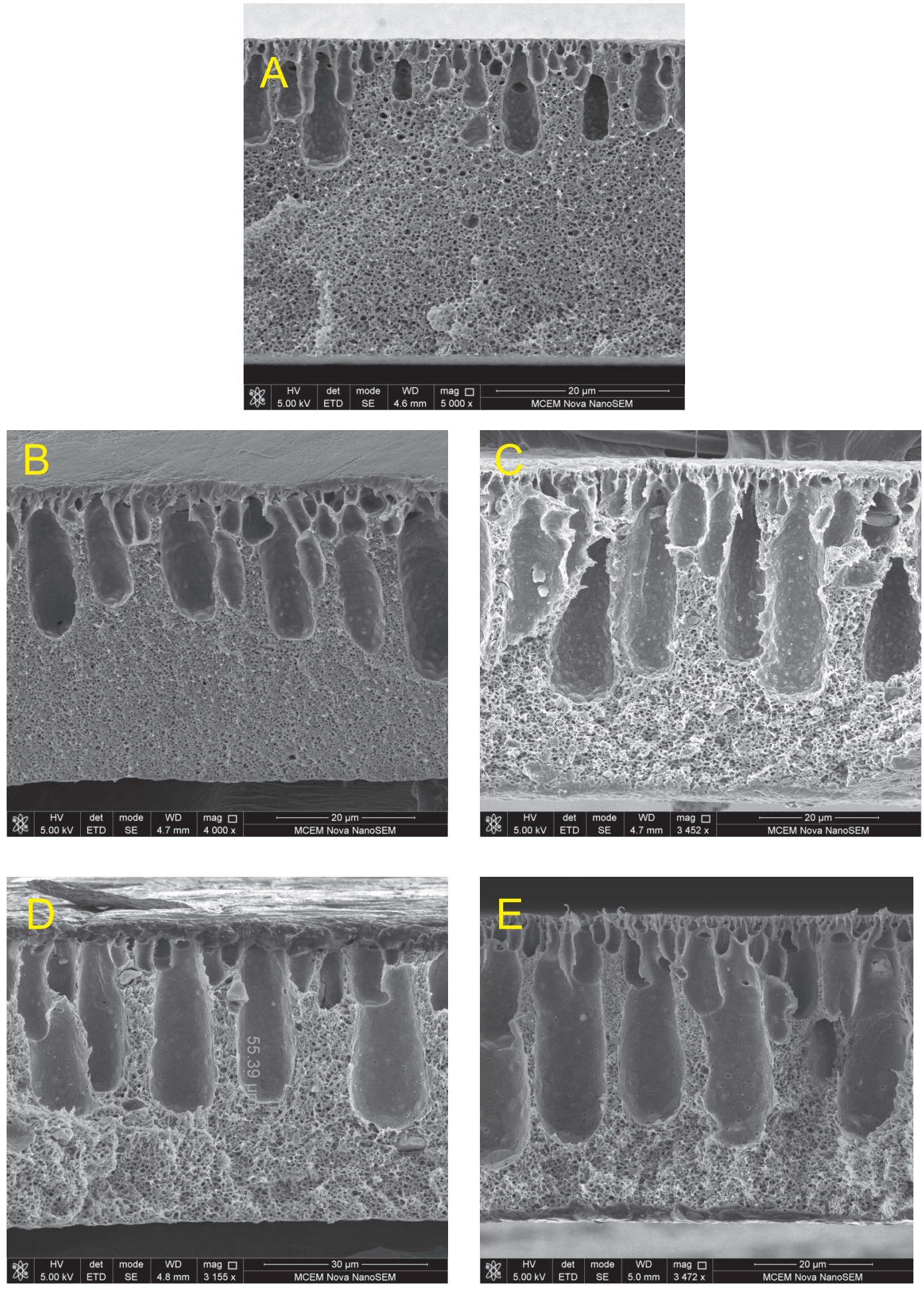

Fig. 5 SEM cross-section morphology of (A) control PVDF membrane. (B) $\mathrm{SiO}_{2} \mathrm{PDMS}_{0.25 \%} \mathrm{PVDF}_{\mathrm{membrane}}$ (C) $\mathrm{SiO}_{2} \mathrm{PDMS}_{0.5 \%} \mathrm{PVDF}$ membrane. (D) $\mathrm{SiO}_{2} \mathrm{PDMS}_{1.0 \%} \mathrm{PVDF}$ membrane. (E) $\mathrm{SiO}_{2} \mathrm{PDMS}_{2.0 \%} \mathrm{PVDF}$ membrane. 


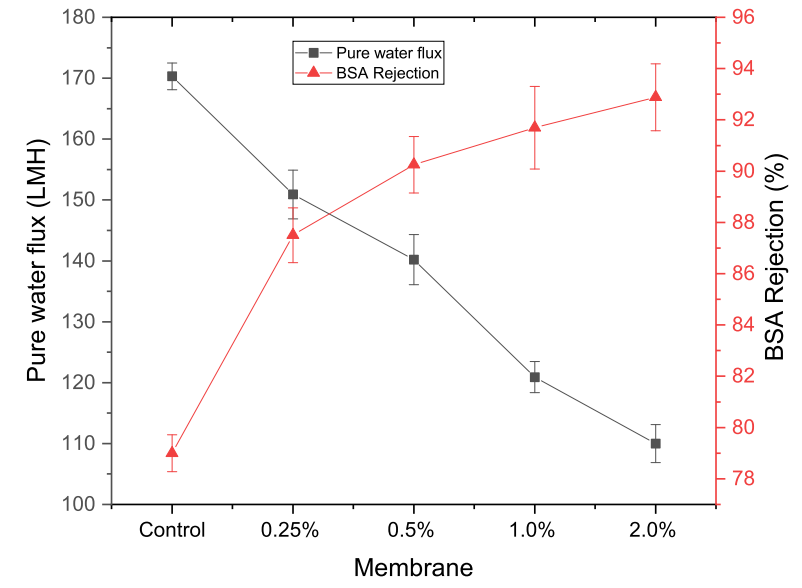

Fig. 6 Pure water flux and BSA rejection of control PVDF membrane and mixed matrix membranes, where the percent label indicates the loading of PDMS- $-\mathrm{SiO}_{2}$ nanoparticles in the mixed matrix membranes. The reported value is the average of five measurements and the error bars represent one standard deviation.

contributed to the reduction of water flux.

As discussed previously, the antifouling ability of membranes could be improved by increasing the surface hydrophilicity. However, interestingly, the results of water contact angle and BSA rejection revealed that the membrane with lowest hydrophilicity (i.e., highest water contact angle) showed highest antifouling performance (i.e., highest BSA rejection). This suggests that surface hydrophilicity is not the only factor affecting membrane antifouling performance. In fact, as also discussed earlier, many factors could affect the antifouling properties. Therefore, it is possible that certain substances possess two or more properties simultaneously which have opposite effect on antifouling performance. For example, although PDMS is hydrophobic which is not favorable in terms of antifouling, the rotational freedom of silicon-oxygen backbone within its structure also hinders foulant adsorption. It is possible that PDMS demonstrated antifouling performance because of the positive effect of its unique chemical structure, and this outweighed the negative effect of its hydrophobic property on antifouling performance.

\section{Antifouling performance of mixed matrix membranes}

As shown in Figure 7 (A), the mixed matrix PVDF membranes showed higher flux recovery ratio (\% FRR) than the control membrane. However, although the mixed matrix PVDF membranes showed higher antifouling performance and higher flux recovery ratio, the absolute water fluxes of the mixed matrix membranes were lower than those of the control membrane, which is not favorable. Future research is needed to increase the absolute water flux and antifouling performance simultaneously.

Static protein adsorption is one of the most important factors in determining the antifouling properties of membranes and the reduction of protein (foulant) on the membrane surface indicated better antifouling property of the membranes. As shown in Figure 7 (B), the static protein adsorption was negatively related to the amount of PDMS-g-SiO ${ }_{2}$ NPs, and the adsorption slashed from $5.21 \mu \mathrm{g} / \mathrm{cm}^{2}$ for control PVDF to 1.99 $\mu \mathrm{g} / \mathrm{cm}^{2}$ for $\mathrm{SiO}_{2}$ PDMS2\%PVDF. The possible explanation was that the presence of PDMS-g-SiO ${ }_{2}$ NPs in the skin layer (as confirmed by SEM morphology, See Figure S1) had the capability to mitigate the adsorption of BSA pollutant. Also, as indicated by Figure S1, incorporating silica nanoparticles has slightly increased the surface roughness, and it is reported that rough surface can reduce fouling due to a higher shear stress which reduces foulant attachment on the surface (reference here: https://pubs.acs.org/doi/pdf/10.1021/acs.est.0c00535). In contrast, flux recovery ratio (\%FRR) was measured again after BSA adsorption and the results were also shown in Figure 7 (B) on the secondary Y-axis. It was observed that \%FRR was higher for all the hybrid PVDF membranes compared to control PVDF. Also, the \%FRR increased as the ratio of nanoparticles increased, which uncovered the positive relationship between flux recovery and fouling resistance. This trend in \%FRR after static adsorption of BSA was consistent with the above discussion. It was expected that membranes with less foulants attached showed higher flux. It is well reported that the existence of nanoparticles has the ability to reduce the adsorption of pollutants such as BSA (reference here: https://doi.org/10.1016/j.mtcomm.2019.100784; https://doi.org/10.1016/j.seppur.2020.116646). However, it does not necessarily mean that higher amount of nanoparticles will always result in higher antifouling performance. This is due to the fact that if a significant amount of nanoparticles is incorporated, the surface roughness will be increased significantly, which will decrease the mobility of the foulants attached on the membrane surface (reference here: https://pubs.acs.org/doi/pdf/10.1021/acs.est.0c00535). As a result, the foulants cannot be easily washed off, making fouling easier to take place. Also, as discussed above, nanoparticle incorporation has a negative effect on the membrane surface hydrophilicity, the latter of which also plays a role in antifouling performance. In short, the current results reveal that within the range of $0-2.0 \%$, nanoparticle incorporation has a positive effect on the anti-fouling performance of the membranes, and future research is needed to investigate the effect of higher amount of nanoparticles.

\section{Conclusions}

The mixed matrix PVDF membranes were prepared via noninduced phase separation (NIPS) method using PDMS-g-SiO ${ }_{2}$ as modifier. The prepared membranes exhibited lower BSA protein adsorption on their surface during static protein adsorption test. Furthermore, the BSA molecules adsorbed onto the top surface of hybrid PVDF membranes were more easily to be washed off during the cleaning. These results revealed that PDMS-g-SiO2 NPs was able to improve the antifouling properties of mixed matrix PVDF membranes, which may be of particular importance to the ultrafiltration industry. 

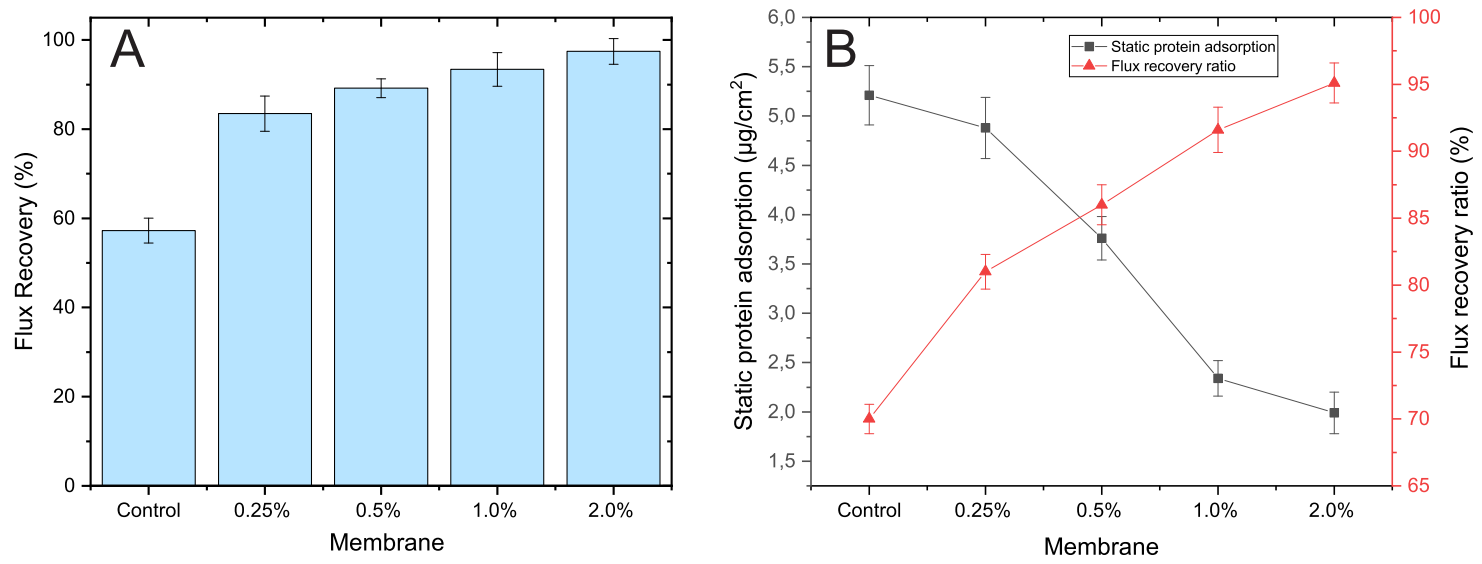

Fig. 7 (A) Flux recovery and (B) Static protein adsorption and flux recovery after protein adsorption, of control and mixed matrix PVDF membranes, where the percent label indicates the loading of PDMS-g-SiO ${ }_{2}$ nanoparticles in the mixed matrix membranes. Reported values are the average of five measurements and the error bars represent one standard deviation.

\section{Experimental section}

\section{Materials}

Commercial $\mathrm{SiO}_{2}$ (fumed) nanoparticles were supplied by Sigma Aldrich, Australia. It was mono-dispersed $7 \mathrm{~nm}$ and had a surface area of $395 \pm 25 \mathrm{~m}^{2} / \mathrm{g}$. Polyvinylidene fluoride (PVDF Solef $6020, \mathrm{Mn}=313 \mathrm{kDa}$ ) was purchased from Solvay and dried at $55{ }^{\circ} \mathrm{C}$ for $12 \mathrm{~h}$ before use. Lithium chloride (LiCl, purity $\geq 99.99 \%$, from Sigma Aldrich) was used as pore-forming agent and dried in oven at $90{ }^{\circ} \mathrm{C}$ for $12 \mathrm{~h}$ before use. $\mathrm{N}, \mathrm{N}$ dimethylacetamide (DMAC, purity $\geq 99 \%$, from Sigma Aldrich), 3-(triethoxysilyl) propionitrile (TESPN, purity 97\%, from Sigma Aldrich), N, N'-diisopropylcarodiimide (DIC, purity 99\%, from Sigma Aldrich), 4-dimethylaminopyridine (DMAP, purity 98\%, from Fluka), polyethylene glycol (PEG, from Sigma Aldrich), sodium hydroxide pellets ( $\mathrm{NaOH}$, from Merck Millipore), and polydimethylsiloxane monohydroxy terminated (PDMS-OH, Mw $=4000 \mathrm{Da}$, from Sigma Aldrich) were used as received. Bovine serum albumin (BSA, $68 \mathrm{kDa}$, agarose gel electrophoresis, from Sigma Aldrich) was used as a model foulant during ultrafiltration experiments.

\section{Synthesis of PDMS-g-SiO ${ }_{2}$ nanoparticles}

PDMS-g- $\mathrm{SiO}_{2}$ nanoparticles were prepared by a three-step synthesis method, including silane coupling, functional group hydrolysis, and finally Steglich esterification, as described by Wu and coworkers. ${ }^{52}$ Briefly, $2 \mathrm{~g}$ of fumed silica nanoparticles were firstly functionalised with TESPN (a nitrile terminated silane coupling agent) at $57{ }^{\circ} \mathrm{C}$. Exposed nitrile groups were then hydrolysed to carboxylic acid in the presence of $\mathrm{HCl} / \mathrm{Milli}-\mathrm{Q}$ water (50:50) vol\% at $72.5^{\circ} \mathrm{C}$ for $12 \mathrm{~h}$ under gentle stirring, providing a reaction site for subsequent esterification. In the third step, $338.4 \mathrm{mg}$ (i.e., $0.0828 \mathrm{mmol}$ ) mono-hydrodxy (terminal) functionalised PDMS (PDMS-OH) was attached to $0.3 \mathrm{~g}$ carboxylic acid functionalised silica nanoparticles by Steglich esterification with $10.45 \mathrm{mg}$ (i.e.,
$0.0828 \mathrm{mmol}$ ) DIC (coupling agent), in the presence of $5.06 \mathrm{mg}$ (i.e., $0.0414 \mathrm{mmol}$ ) DMAP. The overall process of surface functionalization is illustrated in Scheme S1.

\section{Preparation of mixed matrix PVDF membranes}

In this study, mixed matrix PVDF UF membranes were prepared using a non-solvent induced phase separation (NIPS) method.5556 For each membrane, casting solutions were prepared by dissolving different amounts of PDMS-g-SiO ${ }_{2}(0,1.6$, $3.2,6.3,11.8 \%$ ) in $16 \mathrm{~mL}$ DMAC, which was then sonicated for $20 \mathrm{~min}$. $0.426 \mathrm{~g}$ of $\mathrm{LiCl}$ and $3.2 \mathrm{~g}$ of PVDF were then added to this solution successively and the mixture was stirred overnight at $200 \mathrm{rpm}$. The compositions of the casting solutions are summarized in Table 1. The casting solution was then left in a fume cupboard to allow any air bubbles to release. Next, the casting solution was poured onto a clean glass plate and cast using a casting knife (Paul Gardner Co., Inc.) with a $150 \mu \mathrm{m}$ air gap. Then, the membrane was immersed in a coagulation bath of deionised water. After the membrane was solidified, it was peeled off from the glass plate and washed three times with double deionised water (DDI) and stored in fresh DDI before use. ${ }^{3557}$ The prepared series of membranes were labelled as $\mathrm{PVDF}+\mathrm{LiCl}, \mathrm{SiO}_{2} \mathrm{PDMS} x \mathrm{PVDF}$, where $x$ is the mass fraction of PDMS-g-SiO 2 in the mixed matrix membrane.

\section{Characterization}

The chemical structures of the modified membranes were characterized with Fourier Transform Infrared spectroscopy (FTIR) in the range of $4000-600 \mathrm{~cm}^{-1}$ at a resolution of $4 \mathrm{~cm}^{-1}$ and 64 scans. Surface and cross-sectional micrographs were taken by Scanning Electron Microscopy (Magellan SEM, FEI company, America). SEM samples were prepared by drying the samples at room temperature and then coating with a $0.5 \mathrm{~nm}$ layer of Iridium (208 h sputter coater, Cressington, UK). For cross-sectional morphology, the dried membrane samples were fractured in liquid 
Table 2 Mass-percent compositions of the casting solutions and the resulting membranes, where percent values indicate the loading of PDMS-g-SiO 2 in the mixed matrix membranes.

\begin{tabular}{llllll}
\hline Membrane & $\begin{array}{l}\text { PVDF } \\
(\%)\end{array}$ & $\begin{array}{l}\mathrm{LiCl} \\
(\%)\end{array}$ & $\begin{array}{l}\text { DMAC } \\
(\%)\end{array}$ & $\begin{array}{l}\text { PDMS-g-SiO }_{2} \\
\text { (in solution, \%) }\end{array}$ & $\begin{array}{l}\text { PDMS-g-SiO }_{2} \\
\text { (in membrane, \%) }\end{array}$ \\
\hline PVDF control & 15 & 2.0 & 83.0 & 0 & 0 \\
$0.25 \%$ & 15 & 2.0 & 82.75 & 0.25 & 1.6 \\
$0.5 \%$ & 15 & 2.0 & 82.50 & 0.50 & 3.2 \\
$1.0 \%$ & 15 & 2.0 & 82.00 & 1.0 & 6.3 \\
$2.0 \%$ & 15 & 2.0 & 81.00 & 2.0 & 11.8 \\
\hline
\end{tabular}

nitrogen to retain the membrane structure. Elemental analysis of the membrane samples was conducted using EDX equipped Nova NanoSEM 450 (Quantax 400 X-ray analysis system, Bruker, USA). Thermal stability of the prepared membranes was measured using a TA instrument 2950 thermogravimetric analyzer (TGA). Membrane samples were cut into small pieces and loaded into a high temperature platinum pan. The microbalance purge gas was nitrogen (flow rate: $2-2.5 \mathrm{~cm}^{3} / \mathrm{min}$ ) and samples were heated at a rate of $20^{\circ} \mathrm{C} / \mathrm{min}$ up to $1000^{\circ} \mathrm{C}$ under oxygen atmosphere (flow rate: $10 \mathrm{~cm}^{3} / \mathrm{min}$ ).

Water contact angles of the membranes surface were measured by the sessile drop technique using a contact angle goniometer (PGX+, Fibro System Ab, Sweden). Membrane samples were cut into the size of $1 \mathrm{~cm} \times 6 \mathrm{~cm}$ and an average of five measurements on at least two samples of each membrane, were recorded. To calculate membrane porosity, the membrane sample was soaked in water for $3 \mathrm{~h}$ and then the mass was measured, and then the same membrane was dried in vacuum oven at $60{ }^{\circ} \mathrm{C}$ and then the mass was measured again. The membrane porosity was calculated according to Equation 1 15859 where $W_{W}$ is the weight of the wet membrane $(\mathrm{g}), W_{D}$ is the weight of the dry membrane (g), and $\rho_{p}$ and $\rho_{W}$ are the densities of the polymer and water ( $g$ $\left.\mathrm{cm}^{-3}\right)$.

$$
\varepsilon(\%)=\frac{\frac{W_{W}-W_{D}}{\rho_{W}}}{\frac{W_{W}-W_{D}}{\rho_{W}}+\frac{W_{D}}{\rho_{p}}}
$$

Molecular weight cut-off (MWCO) and solute rejection were determined using a series of $1 \mathrm{~g} / \mathrm{L}$ of polyethylene glycol (PEG) solutions, prepared by adding PEG of varying molecular weight $(35,100,200 \mathrm{kDa})$ to deionized water. PEG rejection rates were calculated from the concentrations of PEG in the feed solution $\left(C_{f}\right)$ and permeate water $\left(C_{P}\right)$ using a total organic carbon analyser (TOC-LCSH, Shimadzu, Japan). The pore size of the membranes was then estimated based on the values of MWCO of the membrane according to Equation 2 ${ }^{60}$ where $r$ is the pore size of membrane (nm), MWCO is the molecular weight cut-off $(\mathrm{g} / \mathrm{mol})$, and was calculated by interpolating measured rejection rates to a rejection of $90 \%$.

$$
r=0.262 \sqrt{\mathrm{MWCO}}-0.3
$$

Pure water flux of the unmodified PVDF and modified PVDF membranes was measured using a dead-end cell filtration unit (HP4750 stirred cell, Sterlitech, USA). The membrane samples had a diameter of $49 \mathrm{~mm}$ and effective membrane area of 14.6 $\mathrm{cm}^{2}$. The filtration cell was filled with $300 \mathrm{~mL}$ double deionized water (DDI) and then connected to $5 \mathrm{~L}$ dispensing vessel. Compressed nitrogen gas was used to control the feed pressure. The collected permeate was determined using an electronic balance with mass change recorded automatically with the connected LabView software. During the filtration test, membrane samples were precompacted first at $150 \mathrm{kPa}$ for at least $1 \mathrm{~h}$ to stabilise the flux, which was then recorded at a pressure of $100 \mathrm{kPa}\left(J_{w_{1}}\right)$. At least five membrane samples were tested and the average flux values were calculated. Constant transmembrane fouling mode was used in this study to determine the fouling resistance of the membranes. DDI water was exchanged for a BSA protein solution (1 $\mathrm{g} / \mathrm{L}$, prepared using phosphate buffer saline, $\mathrm{pH}=7.4$ ). The flux $\left(J_{\mathrm{BSA}}\right)$ was recorded at the last 10 minutes during the $1 \mathrm{~h}$ operating period. BSA concentrations in the feed and permeate side were measured spectroscopically at $280 \mathrm{~nm}$ using Varian Cary 100 Bio UV-VIS spectrophotometer. The protein rejection ratio of the membrane was calculated according to Equation 3 , w here $R(\%)$ represented the rejection coefficient of the membrane, $C_{f}$ and $C_{P}(\mathrm{mg} / \mathrm{mL})$ were the protein concentration of feed and permeate streams, and the concentration of BSA in the solution was calculated based on the calibration curve prepared in advance.

$$
R(\%)=\left(1-\frac{C_{P}}{C_{f}}\right) \times 100
$$

After testing, the fouled membranes were physically and chemically cleaned. For physical cleaning, the membranes in the filtration cell were rinsed twice with DDI for $20 \mathrm{~min}$. For chemical cleaning, $100 \mathrm{~mL}$ of $\mathrm{NaOH}$ solution $(2 \mathrm{~g} / \mathrm{L}, \mathrm{pH}=12$ ) was added to the filtration cell and stirred for $20 \mathrm{~min}$ before being rinsed three times with DDI to wash off the $\mathrm{NaOH}$ solution. After each cleaning step, the membrane flux was recorded at $100 \mathrm{kPa}\left(J_{w_{2}}\right)$. To determine the performance of membranes, flux recovery ratio of membranes was calculated by comparing the flux after each cleaning cycle to the flux before fouling using Equation 4.

$$
\operatorname{FRR}(\%)=\frac{J_{w_{2}}}{J_{w_{1}}} \times 100
$$

The amount of protein adsorbed on the membrane surface was determined using static protein adsorption experiments. Adsorption capacity of BSA macromolecules was evaluated by exposing the top surface of hybrid PVDF membranes (diameter $25 \mathrm{~mm}$ ) to a BSA solution $(1 \mathrm{mg} / \mathrm{L})$ in a stirred cell. The stirred cell was then incubated in a shaker (150 rpm agitation) at $30{ }^{\circ} \mathrm{C}$ for $24 \mathrm{~h}$ to reach the adsorption-desorption equilibrium. The amount of protein adsorbed on the top surface of membranes was calculated from the reduced concentration of the BSA solution using Equation 5 , where $Q$ is protein adsorbed $\left(\mathrm{mg} / \mathrm{cm}^{2}\right), C_{b}$ was the final 
concentration of BSA $(\mathrm{g} / \mathrm{L}), A$ was the area of membranes $\left(\mathrm{cm}^{2}\right)$, and $V$ was the volume of BSA solution (L).

$$
Q=\frac{\left(C_{a}-C_{b}\right) V}{A}
$$

The concentration of BSA was determined based on the absorbance at $280 \mathrm{~nm}$ using a UV spectrophotometer (UV mini1240, Shimadzu, Japan). The results shown are the average of the protein adsorption of three separate samples. After static protein adsorption, the flux for the fouled membrane was recorded, and then the resulting BSA-fouled membranes were physically and chemically cleaned and the flux was recorded again. The flux recovery ratio was calculated again by comparing the flux before and after physical and chemical cleaning.

\section{Conflicts of interest}

There are no conflicts to declare.

\section{Acknowledgements}

Muayad al-Shaeli acknowledges PhD scholarship support from the Iraqi government. The Monash Centre for Electron Microscopy assisted with microscopy and elemental analysis.

\section{Notes and references}

1 X. Yin, Z. Zhang, H. Ma, S. Venkateswaran and B. Hsiao, Separation and Purification Technology, 2020, 242, 116794 116794.

2 S. Hube, M. Eskafi, K. F. a. Hrafnkelsdóttir, B. Bjarnadottir, M. A. Bjarnadottir, S. r. Axelsdottir and B. Wu, Science of the Total Environment, 2020, 710, 136375.

3 J. Hong and Y. He, Desalination, 2014, 332, 67-75.

4 V. Potapov, R. Fediuk and D. Gorev, Separation and Purification Technology, 2020, 251, 117290-undefined.

5 Y. Huang and X. Feng, Journal of Membrane Science, 2019, 586, 53-83.

6 T. Ahmad, C. Guria and A. Mandal, Journal of Water Process Engineering, 2020, 36, 101289-101289.

7 P. Peeva, T. Knoche, T. Pieper and M. Ulbricht, Separation and Purification Technology, 2012, 92, 83-92.

8 H. Susanto, M. Robbani, T. Istirokhatun, A. Firmansyah and R. Rhamadhan, South African Journal of Chemical Engineering, 2020, 33, 133-140.

9 B. Liu, T. Zhu, W. Liu, R. Zhou, S. Zhou, R. Wu, L. Deng, J. Wang and B. Van der Bruggen, Water Research, 2020, 187, 116435-116435.

10 F. Qu, Z. Yang, X. Li, H. Yu, Z. Pan, G. Fan, J. He and H. Rong, Separation and Purification Technology, 2021, 257, 117877117877.

11 M. Al-Shaeli, S. J. Smith, E. Shamsaei, H. Wang, K. Zhang and B. P. Ladewig, RSC Advances, 2017, 7, 37324-37330.

12 Y. Su, C. Li, W. Zhao, Q. Shi, H. Wang, Z. Jiang and S. Zhu, Journal of Membrane Science, 2008, 322, 171-177.

13 S. Jiang, Y. Li and B. Ladewig, Science of the Total Environment, 2017, 595, 567-583.

14 Z. Ren, X. Cheng, P. Li, C. Luo, F. Tan, W. Zhou, W. Liu,
L. Zheng and D. Wu, Science of the Total Environment, 2020, 739, 140030-140030.

15 M. Al-Shaeli, S. J. D. Smith, S. Jiang, H. Wang, K. Zhang and B. P. Ladewig, Journal of Membrane Science, 2021, 119339.

16 H. Yu, L. Gu, S. Wu, G. Dong, X. Qiao, K. Zhang, X. Lu, H. Wen and D. Zhang, Separation and Purification Technology, 2020, 247, 116889-116889.

17 J. Zhu, S. Zhou, M. Li, A. Xue, Y. Zhao, W. Peng and W. Xing, Journal of Membrane Science, 2020, 612, 118467-118467.

18 X. Chen, G. Huang, Y. Li, C. An, R. Feng, Y. Wu and J. Shen, Water Research, 2020, 181, 115952-115952.

19 Z. Wang, R. Sahadevan, C. Crandall, T. J. Menkhaus and H. Fong, Journal of Membrane Science, 2020, 611, 118327.

20 S. Jiang and B. Ladewig, Current Opinion in Green and Sustainable Chemistry, 2020, 21, 1-8.

21 J. Hester, P. Banerjee and A. Mayes, Macromolecules, 1999, 32, 1643-1650.

22 J. Hester and A. Mayes, Journal of Membrane Science, 2002, 202, 119-135.

23 S. Roy, D. Bhalani and S. Jewrajka, Separation and Purification Technology, 2020, 232, 115940-115940.

24 D. Rana and T. Matsuura, Chemical Reviews, 2010, 110, 24482471.

25 M. Kobayashi, Y. Terayama, H. Yamaguchi, M. Terada, D. Murakami, K. Ishihara and A. Takahara, Langmuir, 2012, 28, 7212-7222.

26 Z. Estephan, P. Schlenoff and J. Schlenoff, Langmuir, 2011, 27, 6794-6800.

27 J. Schlenoff, Langmuir, 2014, 30, 9625-9636.

28 Y. Chang, C.-Y. Ko, Y.-J. Shih, D. Quémener, A. Deratani, T.-C. Wei, D.-M. Wang and J.-Y. Lai, Journal of Membrane Science, 2009, 345, 160-169.

29 S. Chen, J. Zheng, L. Li and S. Jiang, Journal of the American Chemical Society, 2005, 127, 14473-14478.

30 L. Zhou, W. Yuan, J. Yuan and X. Hong, Materials Letters, 2008, 62, 1372-1375.

31 X. Zhao, Y. Su, Y. Li, R. Zhang, J. Zhao and Z. Jiang, Journal of Membrane Science, 2014, 450, 111-123.

32 M. Lejars, A. Margaillan and C. Bressy, Chemical Reviews, 2012, 112, 4347-4390.

33 J. Zhao, X. Zhao, Z. Jiang, Z. Li, X. Fan, J. Zhu, H. Wu, Y. Su, D. Yang, F. Pan, F. Pan and J. Shi, Progress in Polymer Science, 2014, 39, 1668-1720.

34 J. Mark, Accounts of Chemical Research, 2004, 37, 946-953.

35 M. Owen, Comments on Inorganic Chemistry, 1988, 7, 195213.

36 H. Guo, L. Song, J. Hu, T. Lin, X. Li, H. Yu, D. Cheng, Y. Hou, X. Zhan and Q. Zhang, Chemical Engineering Journal, 2021, 420, year.

37 H. Doan, P. Phong Vo, K. Hayashi, K. Kinashi, W. Sakai and N. Tsutsumi, Journal of Environmental Chemical Engineering, 2020, 8, year.

38 H. Sundaram, Y. Cho, M. Dimitriou, J. Finlay, G. Cone, S. Williams, D. Handlin, J. Gatto, M. Callow, J. Callow, 
E. Kramer and C. Ober, ACS Applied Materials and Interfaces, 2011, 3, 3366-3374.

39 H. Sundaram, Y. Cho, M. Dimitriou, C. Weinman, J. Finlay, G. Cone, M. Callow, J. Callow, E. Kramer and C. Ober, Biofouling, 2011, 27, 589-602.

40 S. Madaeni, S. Zinadini and V. Vatanpour, Separation and Purification Technology, 2013, 111, 98-107.

41 M. Rahaman, H. Thérien-Aubin, M. Ben-Sasson, C. Ober, M. Nielsen and M. Elimelech, Journal of Materials Chemistry B, 2014, 2, 1724-1732.

42 K. Kannan, J. Koistinen, K. Beckmen, T. Evans, J. Gorzelany, K. Hansen, P. Jones, E. Helle, M. Nyman and J. Giesy, Environmental Science and Technology, 2001, 35, 1593-1598.

43 W. D'Hollander, L. De Bruyn, A. Hagenaars, P. de Voogt and L. Bervoets, Environmental Science and Pollution Research, 2014, 21, 11856-11866.

44 J. Wang, Y. Liu, T. Liu, X. Xu and Y. Hu, Journal of Membrane Science, 2020, 599, year.

45 N. Li, Y. Tian, J. Zhao, J. Zhang, L. Kong, J. Zhang and W. Zuo, Journal of Membrane Science, 2018, 548, 470-480.

46 L. Jiang, J. Yun, Y. Wang, H. Yang, Z. Xu and Z.-L. Xu, Journal of Membrane Science, 2020, 596, year.

47 Q. Shi, Y. Su, W. Zhao, C. Li, Y. Hu, Z. Jiang and S. Zhu, Journal of Membrane Science, 2008, 319, 271-278.

48 E. Yuliwati, A. Ismail, T. Matsuura, M. Kassim and M. Abdul- lah, Desalination, 2011, 283, 214-220.

49 S. Nunes, M. Sforça and K.-V. Peinemann, Journal of Membrane Science, 1995, 106, 49-56.

50 J. Park, J. Seo, S. Ahn, J. Kim and S. Kang, Journal of Industrial and Engineering Chemistry, 2010, 16, 517-522.

51 B. Jung, Journal of Membrane Science, 2004, 229, 129-136.

$52 \mathrm{H}$. Wu, J. Mansouri and V. Chen, Journal of Membrane Science, 2013, 433, 135-151.

53 A. Cassano, M. Marchio and E. Drioli, Desalination, 2007, 212, 15-27.

54 C. Tanardi, A. Pinheiro, A. Nijmeijer and L. Winnubst, Journal of Membrane Science, 2014, 469, 471-477.

55 S. Jiang, H. Sun, H. Wang, B. Ladewig and Z. Yao, Chemosphere, 2021, 282, 130817-130817.

56 A. Dehban, A. Kargari and F. Ashtiani, Journal of Industrial and Engineering Chemistry, 2020, 88, 292-311.

57 C. Smolders, A. Reuvers, R. Boom and I. Wienk, Journal of Membrane Science, 1992, 73, 259-275.

58 C. Feng, R. Wang, B. Shi, G. Li and Y. Wu, Journal of Membrane Science, 2006, 277, 55-64.

59 N. Li, C. Xiao, S. An and X. Hu, Desalination, 2010, 250, 530537.

60 C. Tam and A. Tremblay, Journal of Membrane Science, 1991, 57, 271-287. 